\title{
O CANDOMBÁ É MAIS ABUNDANTE EM HABITAT SUSCETÍVEL OU PROTEGIDO DE INCÊNDIOS?
}

\author{
Rayane da Silva Barboza ${ }^{1}$; Abel Augusto Conceição ${ }^{2}$ e Frederic Mendes Huges ${ }^{3}$ \\ 1.Bolsista PIBIC/FAPESB, Graduando em Ciências Biológicas, Universidade Estadual de Feira de Santana, e-mail: \\ rsbarboza2@gmail.com \\ 2. Orientador, Departamento de Ciências Biológicas, Universidade Estadual de Feira de Santana, e-mail: abel18@gmail.com \\ 3. Participante do projeto, Departamento de Ciências Biológicas, Universidade Estadual de Feira de Santana, e-mail: \\ fredericmhuges@gmail.com
}

PALAVRAS-CHAVE: Fogo, Micro-habitat, Vellozia

\section{INTRODUÇÃO}

O campo rupestre é uma fitofisionomia que ocorre em altitudes superiores a 900 metros e que apresenta grandes blocos rochosos e se caracteriza por solos litólicos, predominantemente quartzítico e oligotróficos, elevada amplitude diária de temperatura, ventos fortes e restrição hídrica, além da presença de eventos de fogo (Rapini et al. 2008). O candombá (Vellozia aff. sincorana L.B.Sm \& Ayensu) pertence à família das Velloziaceae, e como tal é caracterizado pela presença de bainhas foliares intercaladas por raízes adventícias formando um pseudotronco que protege as gemas do fogo e da insolação (Rapini et al. 2008) e por sua floração exclusiva após a presença do distúrbio de fogo (Silva 2013). Esses indivíduos ocorrem tanto em ambiente de vegetação contínua, onde são mais expostos a eventos de fogo, quanto em afloramentos rochosos, onde o fogo geralmente não consegue adentrar (Neves \& Conceição, 2010). Fatores como o uso pela população combinado com a sua distribuição restrita, já que o Candombá é uma planta endêmica do PNCD (Conceição et al. 2013; Conceição \& Orr, 2012), faz com que a espécie esteja ameaçada de extinção (Oliveira et al. 2013). O fenômeno do aquecimento global (IPCC 2014) combinado com a frequência de incêndios nessas áreas e com regime hídrico reduzido intensifica ainda mais essa problemática. Neste trabalho buscamos contribuir para o conhecimento a cerca dessa fitofisionomia que segundo Scarano (2007) se trata de um hábitat pouco conhecido pela ciência, além de estudar essa espécie que domina o cenário local. $\mathrm{O}$ objetivo deste trabalho foi relacionar a ocorrência dessa espécie com afloramentos rochosos no setor norte do PNCD. Esperávamos encontrar associação negativa entre a abundância de candombás e porcentagem de rocha e positiva para porcentagem de substrato e sua profundidade já que, segundo Scarano (2007) os ambientes de afloramento rochoso são edaficamente controlados. Quanto ao efeito da cobertura de vegetação sobre a riqueza de espécies, esperávamos associação positiva por estar relacionado com a formação de ilhas de fertilidade (Conceição \& Pirani, 2005).

\section{MATERIAL E MÉTODOS OU METODOLOGIA (ou equivalente)}

O trabalhado foi realizado na Serra do Candombá (Latitude: -12.63659 ${ }^{\circ}$, Longitude: $41.49870^{\circ} ; 1,210$ metros acima do nível do mar) no PNCD, no município de Palmeiras, Bahia, Brasil. Os dados foram coletados entre os dias oito e dez de novembro de 2015.Para o estudo foram montadas três parcelas de 4 x $25 \mathrm{~m}^{2}\left(100 \mathrm{~m}^{2}\right)$ em diferentes afloramentos rochosos, essas parcelas foram subdivididas em 100 quadrículas de $1 \mathrm{~m}^{2}$. Em cada uma dessas trezentas quadrículas foram coletados dados como: profundidade do solo, porcentagem de cobertura de rocha, substrato, vegetação e do candombá, em específico. Para medidas de profundidade de 
solo, utilizou-se uma haste metálica que foi introduzida em vários pontos da quadrícula, mas foi levada em consideração apenas a maior medida. Medidas de cobertura foram obtidas em unidades de pixels, pelo programa ImageTool 3.0 (UTHSCSA, 1995-2002), com base em fotografias de cada quadrícula das parcelas. Para testar a hipótese de associação entre cover e riqueza de espécies, empregamos a métrica de associação de Spearman em função do comportamento não-paramétrico dos dados (teste de Shapiro-Wilk, $P<0,05$ ). Para preditores com distribuição normal $(P>0,05)$ empregamos a métrica de associação de Pearson. De modo similar testamos a associação entre profundidade, \% de solo e \% rocha, e a abundância de candombá. As métricas de associação ( $r$ ) podem variar de -1 (associação negativa máxima) e 1 (associação positiva máxima). As análises foram conduzidas no programa PAST 3.12 (Hammer, 1999-2016).

\section{RESULTADOS E/OU DISCUSSÃO (ou Análise e discussão dos resultados)}

A densidade dos candombás nas três parcelas foi de 0,47indiv. $/ \mathrm{m}^{2}(4,39$ e 98 espécimes de candombás nas P1, P2 e P3, respectivamente). Podemos notar que, à medida que a porcentagem de substrato aumenta da P1 a P3, a abundância de candombás segue o mesmo padrão, e segue um padrão contrário em relação à porcentagem de rocha, isto é, inversamente proporcional (Tabela1). Essa relação é confirmada com as métricas de correlação (Tabela 2), visto que nas três parcelas as associações foram positivas para a abundância de candombá, porcentagem de solo, vegetação e profundidade do solo, e negativa para porcentagem de rocha. Todos os valores foram significativos $(P<0,01)$, exceto a associação entre \%Candombá e as variáveis \%Rocha, \%Solo e \%Vegetação. Na P1, entretanto, não observamos associação entre Candombás e as variáveis analisadas $(P \approx 0,60)$, o que pode ter sofrido interferência da quantidade reduzida de indivíduos de candombá na parcela.

Tabela 01: Descrição do microhabitat das parcelas estudadas.

\begin{tabular}{|c|c|c|c|c|}
\hline & $\begin{array}{l}\text { Profundidade } \\
\text { do solo }\end{array}$ & \%Rocha & $\%$ Solo & $\begin{array}{l}\mathrm{N}^{\circ} \text { de } \\
\text { candombás }\end{array}$ \\
\hline \multirow[t]{2}{*}{ Parcela 01} & $4,1 \pm 4,7 \mathrm{~cm}$ & $80 \pm 22 \%$ & $17 \pm 20 \%$ & \\
\hline & $(0-22,0 \mathrm{~cm})$ & $(26-100 \%)$ & $(0-69 \%)$ & 4 \\
\hline \multirow[t]{2}{*}{ Parcela 02} & $9,1 \pm 7,1 \mathrm{~cm}$ & $70 \pm 26 \%$ & $26 \pm 24 \%$ & \\
\hline & $(0,5-33,3 \mathrm{~cm})$ & $(0-100 \%)$ & $(0-100 \%)$ & 39 \\
\hline \multirow[t]{2}{*}{ Parcela 03} & $9,4 \pm 7,5 \mathrm{~cm}$ & $56 \pm 35 \%$ & $40 \pm 35 \%$ & \\
\hline & $(0-29,5 \mathrm{~cm})$ & $(0-100 \%)$ & $(0-100 \%)$ & 98 \\
\hline
\end{tabular}


Tabela 02: Associação entre as variáveis.

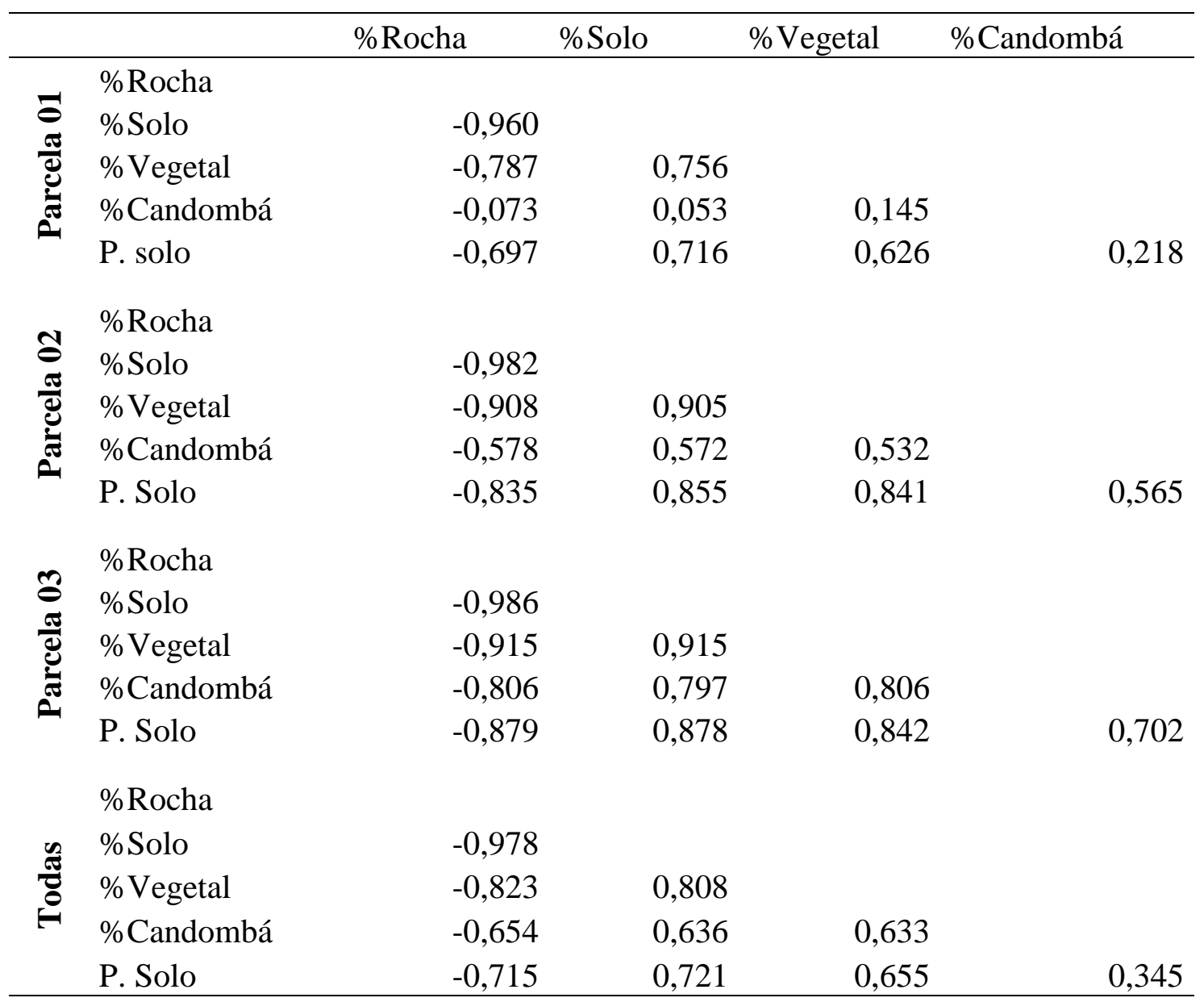

Lengenda: "P. Solo" refere-se à profundidade do solo.

\section{CONSIDERAÇÕES FINAIS (ou Conclusão)}

A partir dos nossos resultados confirmamos nossa hipótese de associação positiva entre a abundância de candombás e as variáveis de solo (\%solo, e profundidade). Conforme salientado por Scarano (2007), ambientes de afloramentos rochosos são edaficamente controlados, ou seja, a ocorrência e abundância de espécies vegetais nestes ambientes estão condicionadas às ilhas de fertilidade. Entretanto, mesmo com a possibilidade de ocorrência de espécimes de candombá sobre afloramentos rochosos, o sucesso reprodutivo destes indivíduos será improvável diante da necessidade de eventos de fogo para a indução da fenofase de floração (Conceição \& Orr, 2012). Além disso, a densidade observada no presente estudo (0,47 indv. $\left./ \mathrm{m}^{2}\right)$ foi menor que a densidade observada no estudo feito em habitat contínuo, $(1,68$ indv./m²; Silva 2013), ou seja, a ocupação desses afloramentos está associada à anemocoria, entretanto há limitação de sítios específicos para estabelecimento. Dessa forma podemos concluir provisoriamente que o candombá é mais abundante em habitat contínuo mais suscetível a incêndios. 


\section{REFERÊNCIAS}

CONCEIÇÃO AA, ALENCAR TG, SOUZA JM, MOURA ADC, SILVA GA (2013) Massive post-fire flowering events in a tropical mountain region of Brazil: high episodic supply of floral resources. Acta bot bras 27:847-850.

CONCEIÇÃO AA, ORR BJ (2012) Post-fire flowering and fruiting in the caulescent rosette Vellozia sincorana, an endemic plant to the Northeast of Brazil. Acta bot bras 26:94-100

CONCEIÇÃO AA, PIRANI JR (2005) Delimitação de habitats em campos rupestres na Chapada Diamantina: substratos, composição florística e aspectos estruturais. Bol Bot Univ. São Paulo 23:85-111

CONCEIÇÃO, A.A., PIRANI, J.R. \& MEIRELLES, S.T. 2007. Floristics, structure and soil of insular vegetation in four quartzite-sandstone outcrops of "Chapada Diamantina", Northeast Brazil. Revista Brasileira de Botânica 30:641-656.

HAMMER, O., Harper, D.A.T., Ryan, P.D.2001. PAST: Paleontological Statistics software package for education and data analysis. Palaeontologia Electronica 4(1): 9pp.

http://ddsdx.uthscsa.edu/dig/download.html

IPCC, 2014: Climate Change 2014: Mitigation of Climate Change. Contribution of Working Group III to the Fifth Assessment Report of the Intergovernmental Panel on Climate Change [Edenhofer, O., R. Pichs-Madruga, Y. Sokona, E. Farahani, S. Kadner, K. Seyboth, A. Adler, I. Baum, S. Brunner, P. Eickemeier, B. Kriemann, J. Savolainen, S. Schlömer, C. von Stechow, T. Zwickel and J.C. Minx (eds.)]. Cambridge University Press, Cambridge, United Kingdom and New York, NY, USA.

NEVES, S. \& CONCEIÇÃO, A. 2010. Campo rupestre recém-queimado na Chapada Diamantina, Bahia, Brasil: plantas de rebrota e sementes, com espécies endêmicas na rocha. Acta Botanica Brasilica 24:653-663.

OLIVEIRA, RCS; SCHMIDT, IB; CONCEIÇÃO, AA (Org.). Uso e Conhecimento do Candombá. Feira de Santana: editora UEFS, 2013.

RAPINI, A., RIBEIRO, P.L.U.Z., LAMBERT, S. \& PIRANI, J.R. 2008. A flora dos campos rupestres da Cadeia do Espinhaço. Megadiversidade 4:16-23.

SCARANO FR (2007) Rock outcrop vegetation in Brazil: a brief overview. Revista Brasileira de Botânica, 30:561-568.

SILVA GA (2013) Florística e estrutura de campos rupestres com diferentes tempos desde o último incêndio, Chapada Diamantina, Brasil. Dissertação, Universidade Estadual de Feira de Santana.

UTHSCSA ImageTool Version 3.0 Final [Internet]. Available from: http://ddsdx.uthscsa.edu/dig/download.html 